\title{
Assessment of Daylight Intensity as a Function of the Ratio of the Window Area and Total Room Volume for Office Buildings in Jos, Nigeria
}

\author{
Ademola Olatunji Jimoh, Olabode Michael Ogunrayewa \\ Faculty of Environmental Sciences, Dept. of Architecture University of Jos, Jos City, Nigeria \\ Email address: \\ ademolajimoh@yahoo.com (A. O. Jimoh), ogunrayewa@yahoo.com (O. M. Ogunrayewa)
}

\section{To cite this article:}

Ademola Olatunji Jimoh, Michael Olabode Ogunrayewa. Assessment of Daylight Intensity as a Function of the Ratio of the Window Area and Total Room Volume for Office Buildings in Jos, Nigeria. International Journal of Environmental Monitoring and Analysis.

Vol. 3, No. 3, 2015, pp. 173-179. doi: 10.11648/j.ijema.20150303.19

\begin{abstract}
The subjective data for this study was obtained from questionnaires while the objective data was obtained from measurement instruments. An $80 \%$ combined votes of respondents found the level of lighting inadequate. This is in consonance with objective measurements, which show interior light level way below recommended standards for the building under research. This has led to the wasteful use of energy for lighting purposes in the day time. However, day light intensity increases as the day proceeds. Also, a linear relationship between the ratio of Operable Window Area to Total Office Volume and day light intensity was established. The lower the Operable Window Area to total Office Volume Ratio, the lower the day light intensity. Hence, by simple linear regression analysis, it concluded that the ratio of operable window area to total room volume of 0.0273 would be required for an acceptable indoor day light intensity of 400 lux in East-Facing Office Buildings with $5 \mathrm{~mm}$ clear glass windows in Jos, Nigeria. However, all the offices studied showed an insufficient average ratio of 0.0023 .
\end{abstract}

Keywords: Daylight Intensity, Working Surfaces, Window Area, Office Buildings

\section{Introduction}

Adequate daylighting is an essential component of a function interior space. It provide comfort, distinct ambience and thus human satisfaction to the users of these architectural spaces. Its uniqueness is accentuated by its changeability as the day progresses or as season and weather changes. The daylight intensity required in an office environment is directly dependent on the type of work being executed. For instance, work that involves minute detailing would require greater amount of light as oppose to work that are bulky or physically exerting. Studies revealed that brighter office lighting can increase employee performance by more than $10 \%$ and that $68 \%$ of employees complain about the light in their offices as being inadequate $[1,2]$.

In modern office environment, task executed are either paper or computer based. In both instances, the source of light with regards to position of the workers and the surface where work is executed is crittical of optimum productivity. Light intensity is measured in units of LUX - lumens per square metre. 400 lux is recommended for routine office works such as typing and filling, while 600 lux for work such intensive reading of text on paper [3]. However, Illuminating Engineering Society of North America (IESNA) recommends 300 lux if computer use is intensive and 500 lux if it is intermittent within the office environment [4]. Research shows that 400-500lux is generally preferred on desk surfaces and for intensive computer use. [5].

In modern office environment, considerations are no longer limited to adequate lighting on the horizontal or inclined surfaces such as office desk but provision most also be made for the vertical or inclined computer screens [6]. Glares from glossy surfaces such as computer screen and flickering artificial light surfaces are to be avoided [7].

Previous studies evaluating daylight intensity as a function of office indoor comfort were evaluated on the bases of percentage window area to floor area or the degree which the windows are physically opened or closed or in conjunction with other variable such as ambient temperature $[8,9,10]$. To the best knowledge of these authors, none have utilized total interior volume as a variable. For the purpose of this research, the recommended 400 lux for routine office works would be used as standard [3]. 


\section{Aim of the Study}

The aim of this study is to evaluate the relationship between operable window area and total office volume and its effect on light intensity in the office space. This is to establish comfort conditions, in the context of lighting level or intensity in office spaces in Jos, Nigeria.

\section{Methodology of Study}

The study was carried out in the month of April 2014 in Jos, Nigeria. The location had an altitude above sea -level of 1286 meters. The GPS location is given as Lat. (N) $9^{0} 58^{\prime} 01.83$ and Long. (E) $8^{0} 52^{\prime} 21.63$. All offices under study were selected randomly, east-facing and operable windows with curtains fully drawn (where they are installed) as at time of taken readings. The period of study was between $8.00 \mathrm{hrs}$ and 15.00hrs week days.

Measurements were taken at intervals of $8.00 \mathrm{hrs}, 12.00 \mathrm{hrs}$ and $15.00 \mathrm{hrs}$. These conveniently represent opening hours, mid-day break and closing hours of the offices under study (See Fig 9). Measurements obtained were GPS location, Altitude above sea level, Rate of Occupancy in offices, indoor and outdoor Daylight Intensity, operative temperature and Relative Humidity (See Table 1 and 2). Questionnaires were issued to the occupants of these offices for the subjective inputs. The instruments enumerated below were used to obtain objective data as tabulated in Table 2 to Table 4.

\subsection{Global Positioning System}

A Cobra GPS 100 global Positioning System receiver was used to obtained global location of building of interest. This device provided accurate positioning to within 3 meters, if held in any position open to the sky. It offers information as to current positioning, altitude above sea level, bearing and time of the day.

\subsection{Digital Lux Meter}

A Pyle PLMT21 Digital lux Meter was used to measure light quality within a given space. This meter was placed on all working surfaces in the given office space and a cumulative average reading obtained. This device has a range of 0 10,000 LUX (Lumen $/ \mathrm{m}^{2}$ ) and an accuracy level of $\pm 10 \%$ per $\mathrm{m} / \mathrm{s}$ for readings less than 10,000 Lux.

\section{Fieldwork}

The field work consists of obtaining subjective and objective data for the purpose of analysis. Subjective data for this study was obtained from questionnaires while the objective data was obtained from measurement instruments. The purpose of the questionnaire was to obtain inputs as to indoor comfort levels of occupants of these offices in the context of light intensity. While objective data obtained by measurement granted empirical specifics yielding greater understanding to the subjective data from the questionnaire.

\subsection{Sample Area Characteristics}

The studies were executed in the Administrative Building of University of Jos in four (4) different offices within the building Complex. In all, two (2) survey sessions were conducted in this Naturally Ventilated (NV) building with $5 \mathrm{~mm}$ clear glass window pane set in metal frames. This was executed in the month of April 2014. The first session was to obtain objective data using instruments earlier enumerated. There was the need to conduct the instrument data session for all offices simultaneously on same day to ensure integrity and interoperability of data collected. The second session was for the subjective data using the questionnaires.

\subsection{Recorded Environmental Variables}

These values, obtained in Table 1, show details of the survey location. These include GPS determined latitude, longitude and altitude readings of the site as well as the survey dates, prevailing outdoor and environmental variables etc. Table 2 shows indoor environmental variables that also have bearing on office comfort in terms of light intensity.

Table 1. Summary of Survey Locations' Environmental Variables.

\begin{tabular}{lllll}
\hline Space ID & Lat. (N) & Long. (E) & Alt. (M) & Date \\
\hline Outdoor Conditions & $9^{0} 58^{\prime} 01.83$ & $8^{0} 52^{\prime} 21.63$ & 1286 & $9^{\text {th }}$ April 2014 \\
Office 1 & $9^{0} 57^{\prime} 01.83$ & $8^{0} 53^{\prime} 18.63$ & 1286 & $9^{\text {th }}$ April 2014 \\
Office 2 & $9^{0} 57^{\prime} 01.83$ & $8^{0} 52^{\prime} 18.64$ & 1286 & $9^{\text {th }}$ April 2014 \\
Office 3 & $9^{0} 57^{\prime} 01.55$ & $8^{0} 52^{\prime} 22.63$ & 1286 & $9^{\text {th }}$ April 2014 \\
Office 4 & $9^{0} 57^{\prime} 01.55$ & $8^{0} 52^{\prime} 22.63$ & 1286 & $9^{\text {th }}$ April 2014 \\
\hline
\end{tabular}

Where:

Lat: Latitude $\left({ }^{\circ} \mathrm{N}\right)$

Long.: Longitude $\left({ }^{\circ} \mathrm{E}\right)$

Alt.: Altitude (m)

\subsection{Solar Radiation}

In Jos City, the sun rises at about 6.00am and sets between 6.00 and $6.30 \mathrm{pm}$ daily, thus providing almost twelve hours day lighting each day of about equal duration of night or day. This equate to about 9 hours of sunshine daily (See Fig 1). The longest days are obtained between the months of March and June. This research was conducted in the month of April, this 
fall within the period in which the highest amount of sunlight is obtained.

The highest intensity of sunlight occurs between 11.00am and $1.00 \mathrm{pm}$ throughout the year. A daily Solar Radiation average of over $4300 \mathrm{wh} / \mathrm{m}^{2}$ per annum is recorded in the city annually. The early morning sun rises in the East at altitudes of between $8^{\circ}$ and $35^{\circ}$ between $6.00 \mathrm{am}$ to $7.00 \mathrm{am}$ daily throughout the year. For most periods in the year, the sun sets in at relatively low altitudes from the west.

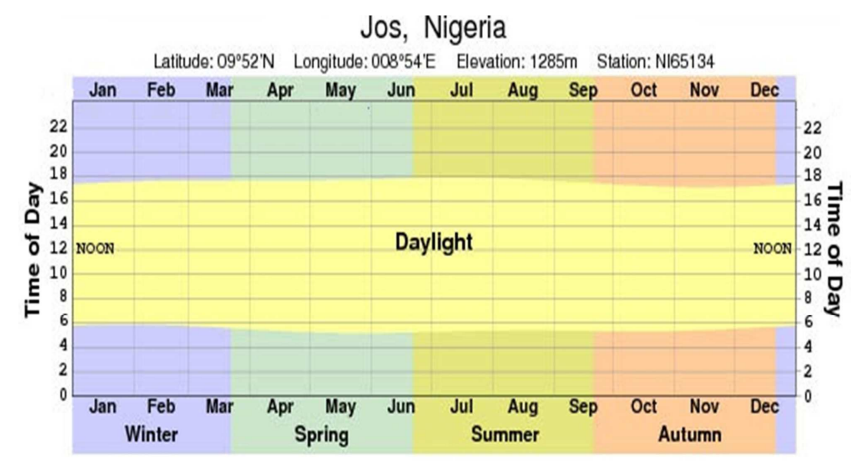

Fig. 1. Annual Solar Radiation. Source: climatecharts.com.

\subsection{Office Characteristics}

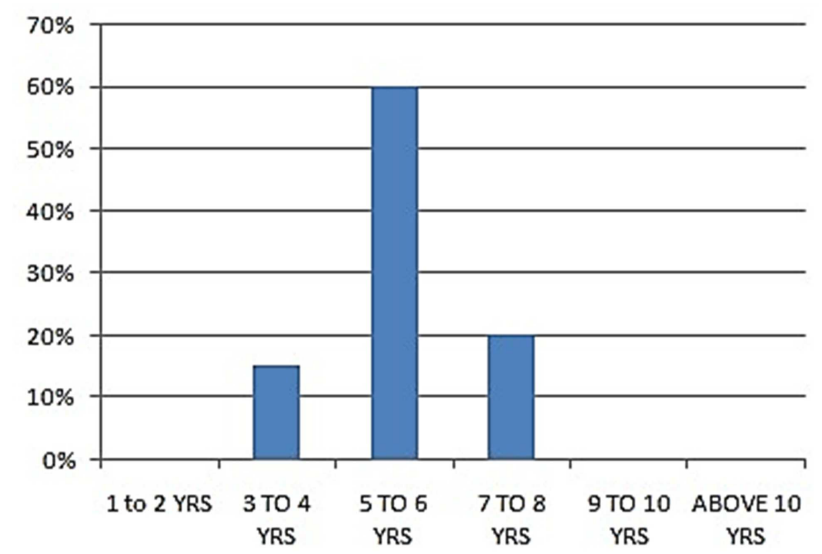

Fig. 2. How long have you been working in this office.

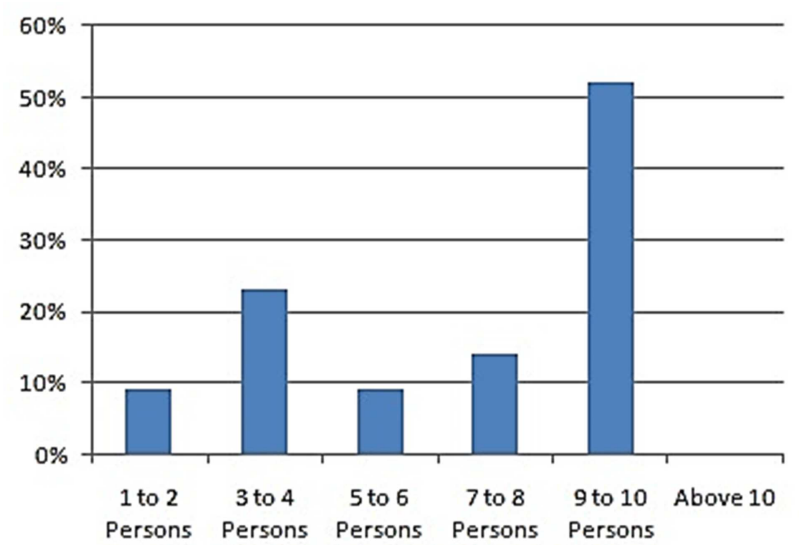

Fig. 3. Office Occupation Distribution and Office Size.

All respondents to questionnaire were brought up in the urban areas. $60 \%$ of respondent have been working in these offices for 5 to 6 yrs (See Fig 2). This fact is crucial in the event of the need to investigate the possibility of acclimatization of the respondent to their environment. 55\% work in offices with 9 to 10 other persons, $15 \%$ work in same office with 7 to 8 other persons. While $30 \%$ work in spaces with less than 7 persons (See Fig. 3).

\subsection{Lighting}

The sun lighting pattern unique to the region indicates that lighting hours varies vary throughout the year (See fig 1). However, office hours in this part of the world, runs between $8 \mathrm{am}$ to $3 \mathrm{pm}$. These are period in which, for most part of the year, natural lighting from the sun is often adequate debarring local weather conditions.

It therefore follows that there should be minimal use of artificial light by the subjects of this research. However, survey reveals artificial light use $75 \%$ of the time between the hours of $6 \mathrm{am}$ and 10am (See Fig 4). These artificial light sources are $74 \%$ Compact Fluorescent Lighting (CFL) of one type or another, while $26 \%$ are energy inefficient filament bulbs (See Fig 5). The preponderance of these energy saving lighting units such as CFL units might not be unconnected with recent Federal Government policy making the use of these electrical energy-saving devices mandatory.

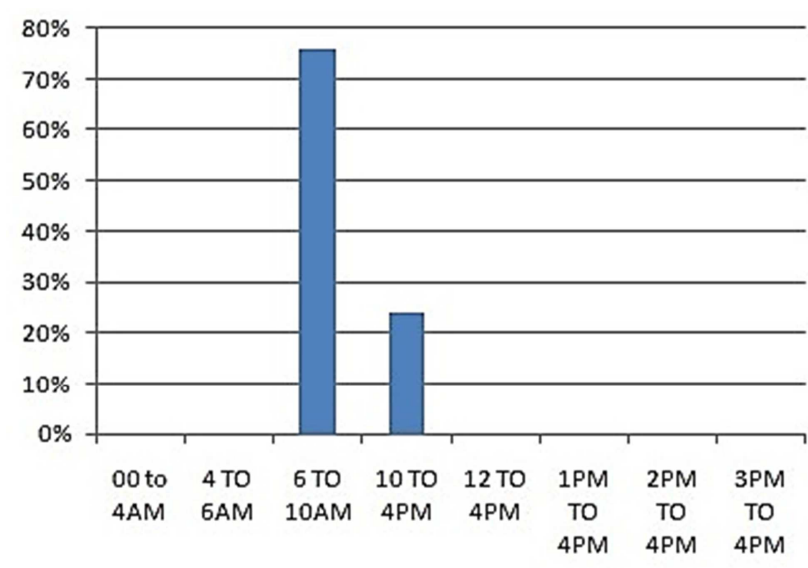

Fig. 4. What Time of The Day Do You Normally Turn on The Lights.

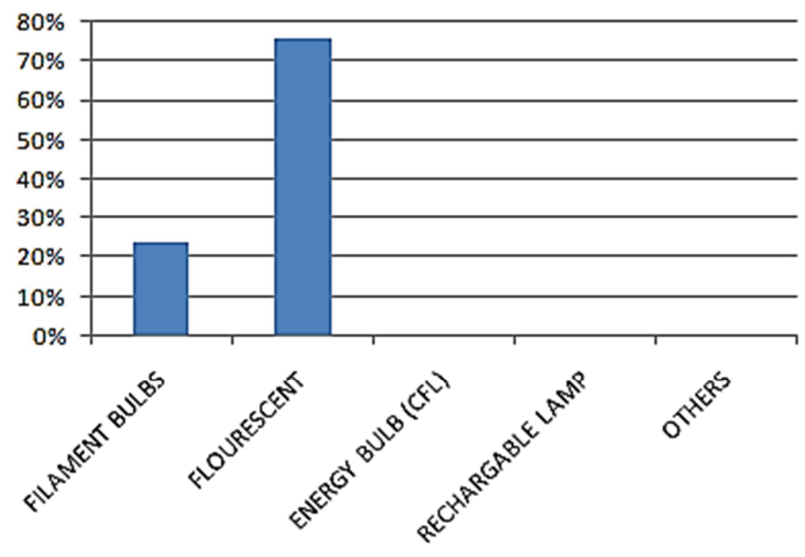

Fig. 5. Light Appliance Type. 
Table 2. Summary of Indoor Climatic, Metabolic and Clothing Variables.

\begin{tabular}{llllll}
\hline Space ID & Sample Size & Vol. $\left(\mathbf{M}^{\mathbf{3}}\right)$ & Ta $(\mathbf{0} \mathbf{C})$ & RH (\%) & LUX \\
\hline Office 1 & 12 & 40.32 & 28.30 & 38.2 & 554 \\
Office 2 & 4 & 50.24 & 26.60 & 43.9 & 256 \\
Office 3 & 15 & 324 & 27.76 & 61.2 & 142 \\
Office 4 & 8 & 75.61 & 29.45 & 42.3 & 278 \\
\hline
\end{tabular}

Where:

Vol: Volume of air/space (Length $\mathrm{x}$ Breadth $\mathrm{x}$ height)

Ta: Air temperature $\left({ }^{\circ} \mathrm{C}\right)$ (average at 2 heights and multiple locations in the room)

Vel: Air velocity $(\mathrm{m} / \mathrm{s})($ average at multiple locations in the room)

RH: Relative Humidity (\%) (Average across multiple locations in the room)

Lux: Lighting level (Lux) (average at task levels across the room)

Table 3. Percentage Area of Windows and Indoor Environmental Variables.

\begin{tabular}{llllll}
\hline Space ID & Sample Size & Vol. $\left(\mathbf{M}^{\mathbf{3}}\right)$ & Wa $\left(\mathbf{M}^{\mathbf{2}}\right)$ & Ra (\%) & LUX \\
\hline Office 1 & 12 & 40.32 & 1.44 & 0.036 & 554 \\
Office 2 & 4 & 50.24 & 1.44 & 0.029 & 327 \\
Office 3 & 15 & 324 & 2.88 & 0.008 & 142 \\
Office 4 & 8 & 75.61 & 1.44 & 0.019 & 278 \\
Average & 9.75 & 122.54 & 1.80 & 0.0023 & 307.5 \\
\hline
\end{tabular}

Where:

Vol: Volume of air/space (Length $\mathrm{x}$ Breadth $\mathrm{x}$ height)

Wa: Window Area (Length $x$ Breadth)

Ra: Ratio of Percentage Area of Window to Room Volume

Lux: Lighting level (Lux) (average at task levels across the room)

\section{Method of Data Analysis}

\subsection{Methods of Subjective Data Analysis}

For subjective data from questionnaires, data presented were analyzed using simple bar graphs and percentages. This is to grant visual correlation to relationships between the variables under study. This enhances understanding of subsequent objectives inputs and inferences.

\subsection{Methods of Objective Data Analysis}

For Objective Data obtained from Measurement Instruments, a bivariate correlation analysis of scatter graph is produced to obtain a perfect +1 for Pearson correlation with a P-Factor (level of significance) of less than 005. This indicating that the two variables are perfectly related in a positive and linear sense. To obtain a predictive value for any value of predictor and dependent variable combination, a regression formula is obtained from the above mentioned bivariate correlation.

\section{Analysis of Findings}

\subsection{Light Intensity Recordings}

Luminance or lighting level is the amount of light falling on a surface so as to allow for acceptable legibility of reading material or the execution of various kinds of visual tasks. It is also described as the total luminous flux incident on a surface, per unit area. Instruments earlier described were used to take readings from three locations: close to window, middle of office and most further from window and an average was thus obtained.

Fig. 8 and Table 2 shows indoor light intensity measurements way below minimum acceptable light level in the offices studied. This light intensity level, at early parts of the day, is certainly not conducive for office-oriented activity as earlier discussed. This explains subjective data which reveals artificial light use $75 \%$ of the time between the hours of $6 \mathrm{am}$ and $10 \mathrm{am}$ (See Fig 4 and 10). The acceptability of indoor light quality also shows $80 \%$ finding it too dull or slightly dull, while $20 \%$ found it slightly bright (Fig. 6). By general perception, $76 \%$ found the lighting level unacceptable.

However, situation improves at the close of the day with an average increase of about 50 lux above what was measured at the start of day. Table 3 shows offices with the lowest ratio of window area to volume ratio having the lowest light intensity level. Fig. 9 shows a linear relationship between window area to volume ratio and light intensity. The lower the ratio, the lower the light intensity.

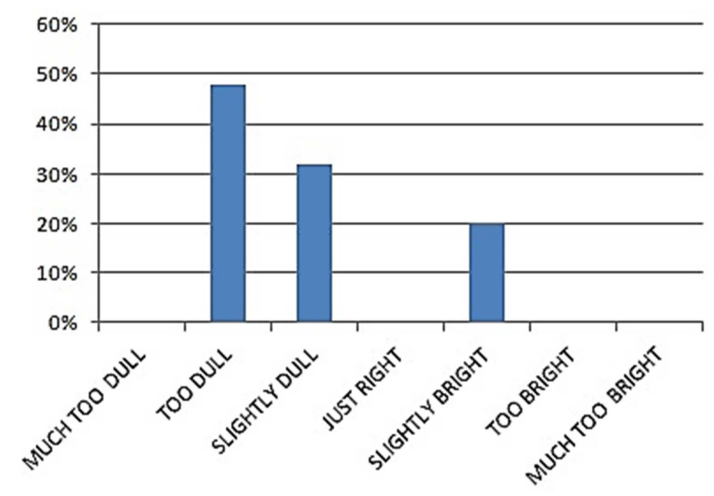

Fig. 6. Rate Your Acceptability of Indoor Light Quality. 


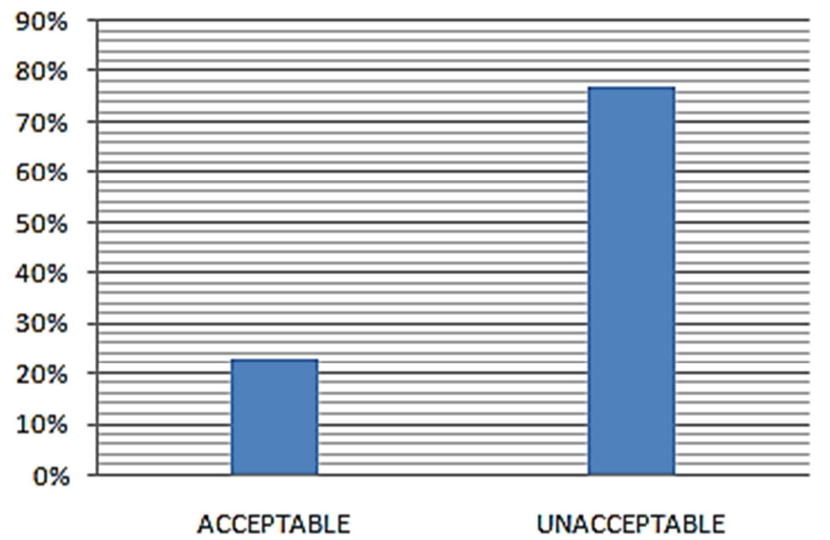

Fig. 7. What is your general perception of lighting in this office.

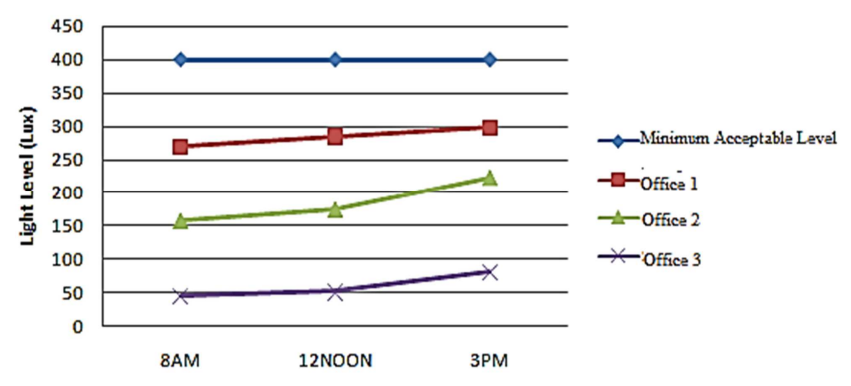

Fig. 8. Showing Interior Light Level.

\subsection{Light Level (Lux) and Window Area to Total Office Volume Analysis.}

A relationship between operable window area and office volume ratio with indoor light intensity was also established. A scatter plot was executed showing visually, a correlation (See Fig. 9). A bivariate correlation confirmed correlation with a Pearson's Correlation index of 1 and a 2 tailed $\mathrm{p}$ factor of $5.6 \%$ (See Table 4). Table 5 shows an $\mathrm{R}^{2}$ value of $89 \%$ indicating considerable fit of data's statistical model of predictor and dependent variable for Window Area Ratio and light intensity. The Coefficient Summary Analysis of Window Area Ratio and light intensity with a p factor $=0.055$ or $5.5 \%$ where the dependent variable is light Intensity is seen in Table 6. This gives a regression formula for any value of light Intensity (Lux) from 100-600 lux as:

$$
\mathrm{y}=\mathrm{bx}+\mathrm{a}
$$

Where;

$$
\mathrm{y}=13278.027(\mathrm{x})+19.855
$$

Therefore, given the recommended minimum light level incidence on working surface for office buildings (i.e. $400 \mathrm{lux}$ ) earlier establish in this research, it would require an operable window area to room volume ratio of 0.0273 to achieve this target. However, Table 3 shows an average ratio of 0.0023 for all the offices under study.

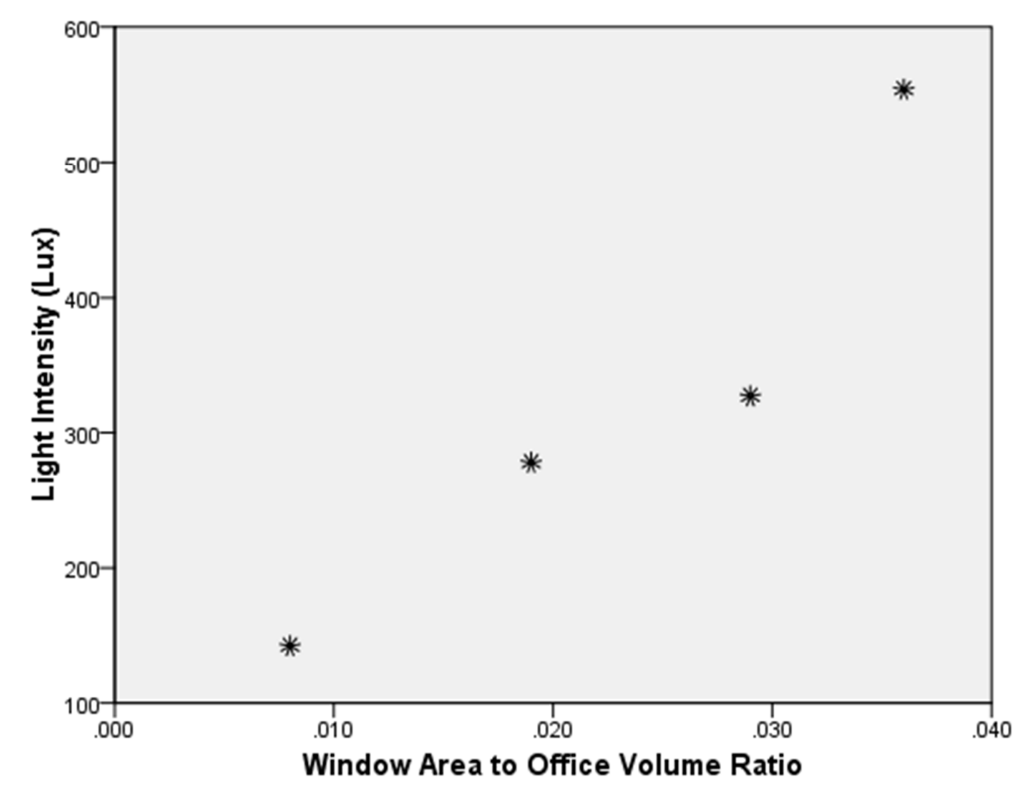

Fig. 9. Scatter Plot Showing relationship between Indoor Light Level and Window Area to Total Office Volume Ratio.

Table 4. showing bivariate correlation relationship between indoor light level and window area to total office volume ratio.

\begin{tabular}{llll}
\hline Correlations & & & WINDOW AREA \% \\
\multirow{4}{*}{ RATIO } & Pearson Correlation & 1 & .945 \\
& Sig. (2-tailed) & 4 & .055 \\
\multirow{2}{*}{ LUX } & N & .945 & 4 \\
& Pearson Correlation & .055 & 1 \\
\hline
\end{tabular}




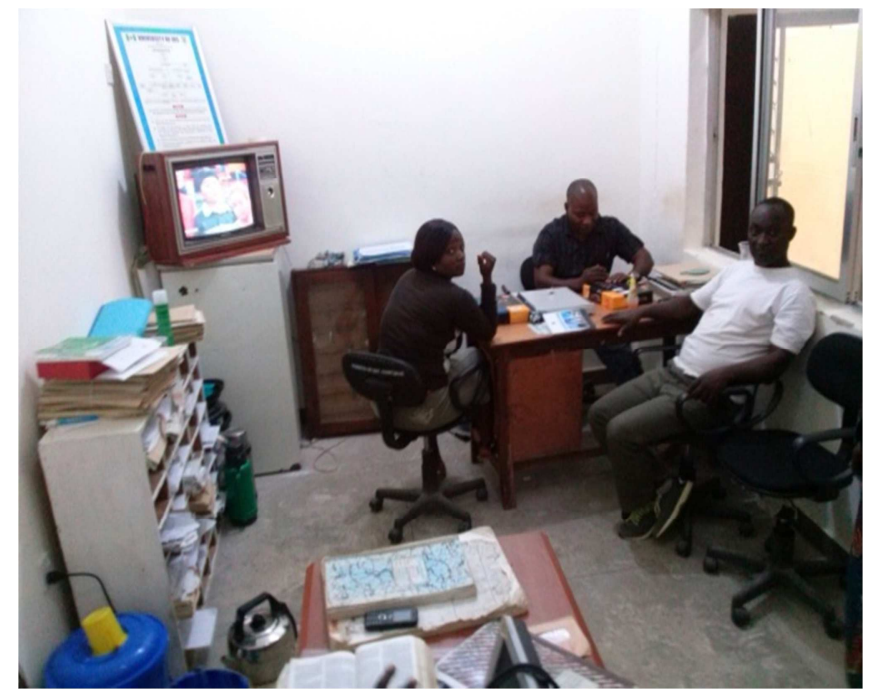

Fig. 10. Typical Office Space Studied.

Table 5. showing $r^{2}$ is $89 \%$ indicating considerable fit of data's statistical model of predictor and dependent variable for light level and window area.

\begin{tabular}{lllll}
\hline Model Summary & & & & \\
\hline Model & $\mathrm{R}$ & $\mathrm{R}$ Square & Adjusted R Square & Std. Error of the Estimate \\
1 & $.945^{\mathrm{a}}$ & .892 & .838 & 68.958 \\
\hline
\end{tabular}

$\mathrm{R}^{2}$ is $89 \%$ showing considerable fit of data's statistical model of predictor and dependent variable.

Table 6. Showing Coefficient Summary Analysis of Light Level and Window Area.

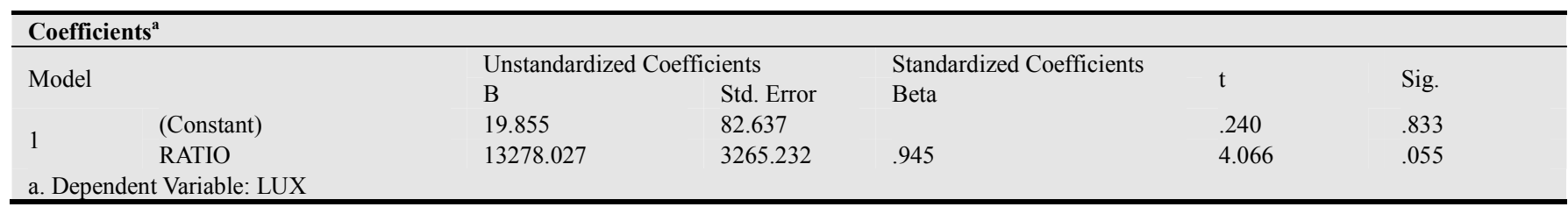

Where $\mathrm{p}$ factor $=0.055$ or $5.5 \%$

\section{Conclusion}

The average light intensity for the offices under study is given as 307.5 Lux (See Table 3). This is way below the 400 Lux recommended minimum standard. The average ratio of the window area and total office volume also shows a low 0.0023 . By calculation, 0.0273 is required to achieve the required 400 lux.

\section{Recommendations}

1. In cash-strapped developing regions, there is need to judiciously utilize an account for the meager energy that is being generated. The optimum utilization of day lighting in offices by applying appropriate window to volume ratios becomes paramount.

2. The research recommends increase in window area to office volume as a mitigating factor to low indoor light intensity level. This can be achieved with a larger window area to total indoor volume.

3. Given the recommended minimum light level incidence on working surface for office buildings (i.e. 400 lux), this research recommend an operable window area to room volume ratio of 0.0273 as oppose to the average 0.0023 .

4. Annual Solar Radiation differs from place to place even within the sub-saharan region. This solar radiation characteristic also varies across the seasons (See Fig 1). There will therefore be need for similar research to be carried out in other regions with differing solar radiation characteristics and at different times of the year or contiguously for a whole year.

\section{References}

[1] Hedge, A., William, R., Sims W. R., and Becker, F.D. (1989) Lighting the Computerized Office. Department of Design and Environmental Analysis New York State College of Human Ecology Cornell University, Ithaca, New York http://ergo.human.cornell.edu/lighting/lilstudy/lilstudy.htm. (accessed Febuary 2015).

[2] Brown, S.K. (2006) "High quality indoor environments for office buildings in: Client Driving Innovation: Moving Ideas $\begin{array}{llll}\text { into } & \text { Practice. } & \text { 12-14 } & \text { (2006): }\end{array}$ http://eprint.qut.edu.au/27229/1/27229.pdf (accessed February 2015). 
[3] ASHRAE/IES 90.1 ANSI/ASHRAE/IES Standard 90.1-2010 (I-P Edition). Energy Standard for Buildings Except Low-Rise Residential Buildings. American Society of Heating, Refrigeration and Air-conditioning Engineers (ASHRAE), Atlanta.

[4] Dilaura, D.L., Houser, K.W., Mistrick, R.G. and Steffy, G.R. (2011)The Lighting Handbook: Reference and Application (IESNA Lighting Handbook). ISBN-13: 978- 0879952419.

[5] Veitch, J.A and Newsham, G.R. (2000) "Preferred luminous conditions in open-plan offices: Research and practice recommendations," Lighting Research and Technology, 32(4), pp. 199-212.

[6] Newsham, G.R. Veitch, J.A. Reinhart, C.F. and Sander, D.M. (2004) Lighting Design for Open-Plan Offices. Construction Technology Update No. 62. 2004 National Research Council of Canada October 2004 ISSN 1206-1220.
[7] Veitch, J.A. and Newsham, G.R. (2013) "Lighting quality and energy-efficiency effects on task performance, mood, health, satisfaction and comfort," in: Establishing Industry Best Practice Criteria for Electric lighting Levels (2013). www.nzgbc.org.nz. (accessed March 2015).

[8] Worthington, J. (2003) Reinventing the Work Place. Copyright 1997, Institute of Advance Architectural Studies. The University of York. (Digital Copy 2003) Anthony Rowe 1td, Eastbourne, London. ISBN 0750628413.

[9] Vimalanathan, K. and Babu, T.R. (2014). The Effect of Indoor Office Environment on the Work Performance, Health and Well-Being of Office Workers. Journal of Environmental Health Science \& Engineering2014,12:113. http://www.ijehse.com/content/12/1/113.

[10] Gibberd, J. and Motsatsi, L. (2015) Are Environmental Conditions in South African Classrooms Conducive for Learning? Department of Architecture, University of Pretoria. https://www.academia.edu/4849243/ (accessed March 2015). 